\title{
Leading Remotely: Competencies Required for Virtual Leadership
}

\author{
M. Elizabeth Azukas' ${ }^{1}$ (1)
}

Accepted: 2 February 2022 / Published online: 4 March 2022

(c) Association for Educational Communications \& Technology 2022

\begin{abstract}
The COVID-19 pandemic caused the largest education system disruption in history, resulting in many districts abruptly, and often ineptly, implementing remote learning to maintain the continuity of instruction. The majority of educational leaders were unprepared for working and delivering instruction in virtual environments. Research indicates that few educational leadership programs provide preparation for leading in virtual learning environments but the COVID crisis made clear that it is imperative for all school leaders have an understanding of virtual leadership. The purpose of this study was to develop an understanding of the competencies required for virtual school leadership as they relate to the Professional Standards for Educational Leaders(P-SEL). Interviews were conducted with 28 virtual leaders using a semi-structured interview protocol. Results indicated that while the P-SEL Standards were categorically aligned to their work, there were distinctive differences in the ways in which virtual school leaders engaged their work across various leadership domains that required unique competencies. These findings are important to our understanding of how to better prepare educational leaders to maintain the effective continuity of instruction in future emergencies as well as to continue to implement and improve upon promising practices that developed during remote instruction.
\end{abstract}

Keywords Virtual leadership · Remote leadership · Virtual leadership competencies

Concerns about virtual leadership quality and preparation existed before the pandemic. Prior to 2020, opportunities for $\mathrm{K}-12$ students to participate in online learning experiences were continuing to expand (Gemin et al., 2015; Molnar et al., 2019), yet research indicated that few educational leadership programs provide any administrator preparation for leading in virtual learning environments (La France $\&$ Beck, 2014). Further, concerns were raised about poor performance on accountability measures in comparison to brick-and-mortar schools (Molnar et al., 2014). Effective leadership is essential, because research has established a link between effective leadership and student achievement, particularly for low income and black students (Andrews \& Soder, 1987; Leithwood \& Jantzi, 2008; Waters \& Marzano, 2007). An understanding of effective leadership is considered particularly critical for online education given that they often serve at-risk students (Abrego \& Pankake, 2010; Quilici \& Joki, 2011-12). Richardson et al. (2015) research

M. Elizabeth Azukas

mazukas@esu.edu

1 East Stroudsburg University of Pennsylvania, East Stroudsburg, PA, USA found that, while virtual school leaders face many of the same categorical challenges as leaders in brick-and-mortar schools, the nuances of these challenges were distinct and they recommended additional research into the specific competencies required for virtual leadership as well as additional pre-service training for leaders.

Amid these developing concerns, the COVID-19 pandemic emerged causing the largest education system disruption in history, impacting 1.6 billion learners in more than 200 countries (Pokhrel \& Chhetri, 2021) resulting in many districts abruptly, and often ineptly, implementing remote learning to maintain the continuity of instruction (Barbour et al., 2020; Hobbs \& Hawkins, 2020; Pokhrel \& Chhetri, 2021). While many have made a point to differentiate emergency remote learning from a more deliberate approach to online learning (Barbour et al., 2020; Hodges et al., 2020) it has become clear that the majority of school principals had to shift their roles from instructional leaders to virtual instructional leaders (Pollock, 2020). Preliminary research has reported that school leaders did not feel adequately prepared to deliver curriculum and instruction online and that many struggled with hardware, software, and infrastructure challenges, preparing teachers to design and facilitate online 
learning, online communication strategies, and managing the physical distance and relationships among school members and constituents (Barbour et al., 2020; Beauchamp et al., 2021; NAESP, 2020; Pollack, 2020; Varela \& Fedynich, 2020). The COVID-19 crisis has made clear that it is imperative for all school leaders have an understanding of the competencies required for virtual leadership. However, to improve virtual leadership, we must have an understanding of the competencies needed for leading virtual schools and how they differ from traditional brick-and-mortar leadership skills so that we can more adequately prepare and support all school leaders. This purpose of this study was to develop a better understanding of the competencies required for virtual school leadership and the extent to which the revised Professional Standards for Educational Leaders (P-SEL) adequately represent these required competencies.

\section{Conceptual Frameworks}

Two conceptual frameworks were used to frame this virtual leadership study. The first is the theory of contextual leadership. Contextual leadership brings the unique situational realities of the environment in which the leader exists to the forefront (Bossert et al., 1982; Day \& Leithwood, 2007; Day \& Gurr, 2014; Gurr \& Day, 2014; Jacobson, et al., 2005; Moos et al., 2011; Noman \& Gurr, 2020). Too often, leadership theories and preparation focus on the individual characteristics of the leaders, with little regard for the contextual factors (Hallinger, 2018), yet the behaviors that are traditionally considered to be effective for leadership may be constrained by the contextual environment (Lord et al., 2001). In virtual schools, the context is a driving factor in the competencies required for effective leadership. During the pandemic, many brick-and-mortar school leaders had to change their behaviors to try to fit the pandemic context. This is consistent with recent studies that have found that leadership is highly contextual and that the most effective leaders are able to adapt their practices to the immediate contextual factors and requirements (Johnson \& Dempster, 2016; Noman \& Gurr, 2020).

The second conceptual framework applied in this study are the Professional Standards for Education Leadership (P-SEL). These standards were developed in the United States in 2015 after a review of empirical research, input from researchers and more than 1000 school and district leaders, and the support of the National Association for Elementary School Principals (NAESP), the National Association for Secondary School Principals (NASSP), and the American Association for School Administrators (AASA) (Professional Standards for Education leaders, 2015). The standards focus on student success and wellbeing and include the following leadership domains:
1. Mission, Vision, and Core Values

2. Ethics and Professional Norms

3. Equity and Cultural Responsiveness

4. Curriculum, Instruction and Assessment

5. Community of Care and Support for Students

6. Professional Capacity of School Personnel

7. Professional Community for Teachers and Staff

8. Meaningful Engagement of Families and Community

9. Operations and Management

10. School Improvement

The standards attempt to provide a strong, clear, emphasis on students and learning outcomes, outlining fundamental principles to ensure that every student is well educated and prepared for the twenty-first century (Professional Standards for School Leaders, 2015). The new standards recognize the importance of human relationships both in leadership and in teaching and student learning and reflect a positive, asset-based approach to promote human development. While grounded in the present, the standards adopt a "future-oriented approach" and they challenge the profession and institutions of higher education to "move beyond established practices and systems and strive for a better future" (Professional Standards for School Leaders, 2015, p. 3). It is important to view virtual leadership competencies through the lens of the P-SEL standards because these standards have influenced education leadership preparation around the country as the National Educational Leadership Preparation (NELP) Program Standards are aligned to the P-SEL standards. The NELP standards are designed for advanced programs at the masters, specialist, or doctoral levels that prepare program directors, supervisors, building level or district level education leaders undergoing accreditation by the Council for the Accreditation of Education Preparation (Professional Standards for School Leaders).

\section{Method}

The purpose of this study was to better understand the competencies required for virtual leadership and whether these aligned to the P-SEL standards. This was accomplished through 28, 60-min interviews with virtual leaders using a semi-structured interview protocol. Interviews were used because they facilitate rich descriptions and detailed accounts of the participants' lived experiences and perspectives on a phenomenon (DiCicco-Bloom \& Crabtree, 2006). Nineteen of the participants were interviewed prior to March of 2020. Nine of the participants were interviewed after March of 2020, during the pandemic. 


\section{Participants}

The population for this study consisted of the National Education Policy Center's 2019 inventory of all full-time virtual schools in the nation, the most recent census of full-time virtual schools (Molnar et al., 2019). Molnar et al. (2019) identified 528 full-time virtual schools in 2015-2016. Schools were categorized based on location, grade levels served, enrollment, student ethnicity, and type of school (charter or district). These categories were then used to sort schools to create a random stratified sample. Internet research was used to obtain leader contact information and 4 cycles of emails were conducted. One hundred virtual school leaders were contacted in total and invited to participate in semistructured 60-min interviews. Eight of these schools were closed and two were listed as separate schools but had the same leader, bringing the total number of leaders contacted to 88 . Twenty-eight leaders responded and agreed to be interviewed, which is a $32 \%$ response rate. This response rate is adequate for this type of research because participants were viewed as "key informants," (Patton, 1990, p. 173) given their knowledge and experience with virtual leadership. Additionally, at the conclusion of the 4th round of interviews, it became apparent that a saturation point was reached where no new data was emerging (Bernard, 2012; Guest et al., 2006; Mason, 2010). Table 1 details the demographic information of the participants.

\section{Data Collection}

Semi-structured interviews (SSIs) were chosen because they fall between structured and unstructured interview processes

Table 1 Virtual school leader participants

\begin{tabular}{|c|c|c|c|c|c|c|c|c|c|}
\hline$\#$ & Pseudonym & Gender & $\begin{array}{l}\text { Years of } \\
\text { Experience }\end{array}$ & Admin Cert & Admin in $\mathrm{f} 2 \mathrm{f}$ & $\begin{array}{l}\text { Virtual Leadership } \\
\text { Role }\end{array}$ & State & Type of School & Configuration \\
\hline 1 & Jennifer & $\mathrm{F}$ & $25+$ & Yes & No & Superintendent & DC & Charter & K-12 \\
\hline 2 & Jeff & M & $25+$ & Yes & Yes & Superintendent & PA & Charter & K-12 \\
\hline 3 & Joseph & M & $15-20$ & Yes & No & Principal & $\mathrm{SC}$ & Charter & $9-12$ \\
\hline 4 & Allison & $\mathrm{F}$ & $15-20$ & No & No & Superintendent & $\mathrm{AR}$ & District & K-12 \\
\hline 5 & Julia & $\mathrm{F}$ & $25+$ & Yes & No & Superintendent & $\mathrm{AZ}$ & Charter & K-12 \\
\hline $6 \mathrm{a}$ & Chris & M & $20-25$ & No & No & Superintendent & WI & District & K-12 \\
\hline $6 \mathrm{~b}$ & Susan & $\mathrm{F}$ & $10-15$ & & & Principal & & & \\
\hline 7 & Edward & M & $25-30$ & No & No & Head of School & WI & District & $9-12$ \\
\hline 8 & Jamie & $\mathrm{F}$ & $25-30$ & Yes & No & Principal & FL & District & K-12 \\
\hline 9 & Holly & $\mathrm{F}$ & $20-25$ & Yes & No & Principal & $\mathrm{AZ}$ & District & K-12 \\
\hline 10 & Andy & $\mathrm{M}$ & $20-25$ & Yes & Yes & Principal & FL & District & $6-12$ \\
\hline 11 & Mandy & $\mathrm{F}$ & $10-15$ & No & No & Superintendent & $\mathrm{AL}$ & K-12 Inc. & $\mathrm{K}-12$ \\
\hline 12 & Michelle & $\mathrm{F}$ & $20-25$ & Yes & No & Principal & $\mathrm{NC}$ & District & $9-12$ \\
\hline 13 & Emily & $\mathrm{F}$ & $20-25$ & Yes & Yes & Superintendent & $\mathrm{NC}$ & District & $9-12$ \\
\hline 14 & Kathy & $\mathrm{F}$ & $20-25$ & Yes & Yes & Principal & PA & Charter & $\mathrm{K}-12$ \\
\hline 15 & Joanna & $\mathrm{F}$ & $20-25$ & Yes & Yes & Principal & PA & District & $9-12$ \\
\hline 16 & Scott & M & $10-15$ & Yes & Yes & Principal & VA & District & $6-12$ \\
\hline 17 & Kathleen & $\mathrm{F}$ & $15-20$ & Yes & No & Principal & MI & District & K-12 \\
\hline 18 & Kelly & $\mathrm{F}$ & $20-25$ & No & No & Principal & GA & Charter & K-12 \\
\hline 19 & Mike & M & $15-20$ & Yes & Yes & Superintendent & $\mathrm{MN}$ & Charter & $6-12$ \\
\hline 20 & Lisa & $\mathrm{F}$ & $15-20$ & Yes & No & Principal & CA & Charter & $6-12$ \\
\hline 21 & Ned & M & $15-20$ & Yes & Yes & Principal & $\mathrm{CO}$ & Charter & $\mathrm{K}-12$ \\
\hline 22 & Lena & $\mathrm{F}$ & $15-20$ & Yes & No & Principal & WA & Charter & $\mathrm{K}-12$ \\
\hline 23 & Diane & $\mathrm{F}$ & $10-15$ & Yes & Yes & Principal & LA & Charter & K-12 \\
\hline 24 & Kevin & M & $10-15$ & Yes & Yes & Principal & IL & District & L-12 \\
\hline 25 & Bobby & M & $15-20$ & Yes & Yes & Principal & $\mathrm{TX}$ & District & $3-12$ \\
\hline 26 & Sallie & $\mathrm{F}$ & $15-20$ & Yes & Yes & Principal & $\mathrm{AZ}$ & Charter & K-12 \\
\hline 27 & Gabe & M & $20-25$ & Yes & Yes & Principal & WV & Charter & K-12 \\
\hline 28 & Vicki & $\mathrm{F}$ & $20-25$ & Yes & No & Superintendent & MA & *Private & $\mathrm{K}-12$ \\
\hline
\end{tabular}

- Private was not a category included in the NEPC listing, however, the original contact listed as a charter school, now works for a private online school 
(Adams, 2015). They are guided, focused, and open-ended communication events co-created by the researcher and the interviewee (Crabtree \& Miller, 1999). This process facilitated the collection of data that would address the study's purpose and objectives, yet allow for a broad understanding of the participant's lived experience. An interview guide was developed using the P-SEL Standards as the basis for questions designed to understand virtual leadership competencies, which was key to obtaining data that addressed the study's research questions (Baumbusch, 2010; Ryan et al., 2009). Questions began at the standard level. For example, "Tell me about your role with regard to developing, advocating, and enacting a shared mission and vision for the school?" and "To what extent are you involved in establishing the core values for the school?" Guiding questions were supported by additional prompts or probes such as, "Can you tell me more?" The interview guide was subject to change to facilitate conversation and to capture any data pertinent to understanding virtual leadership competencies that may not have been directly related to the P-SEL standards (Galleta, 2013). Interviews were conducted and recorded using Zoom.

\section{Data Analysis}

Interviews were transcribed and then analyzed using a hybrid approach of inductive and deductive coding and theme development (Fereday \& Muir-Cochrane., 2006). This allowed me to apply the P-SEL leadership domains as codes as well as to capture any relevant information that did not align with the P-SEL codes. I implemented Fereday and Muir-Cochrane.'s (2006) 6 stages of coding in this hybrid approach. First, I developed the code book using the P-SEL standards. Next, I tested the robustness of the codes against the literature. I then summarized the data and identified initial themes. I applied the P-SEL codebook and then conducted additional coding to identify any themes that may not have been captured by the codebook. Finally, I legitimated and corroborated the coded themes, employing member checking to help improve accuracy, credibility, validity, and transferability (Creswell, 2003; Mertler, 2014).

\section{Results}

The virtual leaders interviewed conveyed that the P-SEL Standards were categorically aligned to their work. Most asserted that they did much of the same work as a brickand-mortar leader, but that there were distinctive differences in the ways in which virtual school leaders engaged their work across various leadership domains. It was clear that the context, particularly the online context, played a role in the types of skills required of effective leaders. One hundred percent of those interviewed who had completed a traditional education leadership program for certification felt that their program did not adequately prepare them for the demands of virtual school leadership. The results are categorized by P-SEL standards, with an emphasis placed on the skills that many brick-and-mortar school leaders had to employ during the pandemic. Table 2 provides a summary of the findings.

Communication and engagement are different in the virtual environment. Jaime, for example, indicated that one of her main roles was developing and enacting a shared mission and vision, for the organization but that it was more challenging in a virtual organization. She stated:

I guess one of the primary differences is obviously you're not seeing everyone every day. And so that means that your approach to how you might deliver and support the vision, mission and the values every day might be a little bit different. As a virtual leader, you really have to be more deliberate about knowing how people are feeling what people are really spending their time on and whether or not the goals that they have as an individual really do line up with your values and goals as an organization.

Communication and engagement challenges also surfaced with regard to the ways in which virtual leaders develop a sense of professional community for teachers and staff. Emily spoke of the need for frequent "pulse checks" and described her tradition of "Text me Tuesdays" in which faculty and staff would send their thoughts, feelings, and questions via text every Tuesday. Mandy instituted "coffee chats" in which teachers and staff could take a coffee break and chat virtually. Chris also expressed the need for connection in the virtual environment so he instituted weekly virtual department meetings and monthly full-day virtual professional learning communities.

Connecting with students and their families presented similar challenges. Virtual school leaders implemented a variety of strategies to help students feel connected in the virtual environment. Holly required teachers to conference individually with students once a month. Joseph invested in school counselors, employing three times the state requirement to reduce the counselor to student ratio. Several of the virtual leaders employed student advisors or coaches that regularly reached out to students to set goals and keep them engaged. Allison has a Student Success Manager that oversees student advisors. She stated, "It is easy for the kids to disengage when they are not required to attend physically and we do not see them, but the Success Manager and advisors have really helped." John hired a Parent Support Coordinator who oversees Parent Ambassadors who run virtual or face to face events every Friday because "if the parents are engaged, the kids do better." The virtual leaders that serve elementary students have to enlist parents as 
Table 2 Virtual competencies summary

P-SEL Standard Virtual Leadership Competencies

Mission, Vision, and Core Values

Ethics and Professional Norms

Equity and Cultural Responsiveness

Curriculum, Instruction, and Assessment
- Many virtual schools have specific missions, i.e. personalized learning, supporting atrisk students, or promoting twenty-first century skills.

- Communicating and promoting the vision must be done virtually.

- Cultivating core values virtually across large (sometimes state-wide communities).

- Expectations for Teacher Professional Norms are different when teachers are working virtually (synchronous vs asynchronous, hours of availability, requirements for officespace, modes of communication, etc.).

- Expectations for School Leaders are also different in the virtual environment (assistant principals, principals, curriculum supervisors, etc.).

- Academic Integrity is a big challenge (students and parents).

- Some states only provide full funding for students that successfully complete courses (can create unique ethical dilemmas).

- Transparency and trust can be harder to develop virtually.

- Perseverance is particularly critical online, particularly if you are supporting at-risk student populations, or students that were already unsuccessful in a brick-and-mortar school.

- Access to technology can be a barrier for students and teachers.

- The visibility of curriculum and instruction necessitates and has necessitated culturally responsive materials.

- There are high levels of diversity in some schools because they draw from across the entire state.

- It can be harder to be culturally responsive when you do not physically see the learners.

- It has been challenging to recruit and retain teachers of color in this alternate environment.

- The elementary students require more parental (or adult) support at home since they are still developing their reading skills. This requires training these adults to be "learning coaches."

- Some states require students to sit in-person for state standardized testing and coordinating the logistics of bringing everyone in from across a region or a state for testing is challenging. It requires event planning and logistics skills.

- Schools that support public school instruction often have difficulty in gaining access to their students' state standardized test scores.

- Online curriculum exists in a "fish-bowl" environment. It can be very public which means it has to be of high-quality and it must adhere to copyright law in a way that is not typically enforced in face-to-face classrooms.

- When curriculum is delivered online, there are legal requirements for accessibility requirements that require detailed knowledge of accessibility laws and the skills to make materials accessible in the online environment.

- It can be challenging to manage rolling enrollment. (In some virtual schools, they do not have typical semesters or marking periods. Students can begin and finish at any time, meaning that students are at all different places in a course. This has implications for systems management, budgeting, and teaching).

- It can be difficult to monitor student progress when students are on rolling enrollment and working at their own pace. This makes planning for student interventions more challenging and has budget implications for schools that only receive full FTE for students who successfully complete courses.)

- You have to manage synchronous and asynchronous instruction.

- Device-agnostic technical tools are required to deliver content and instruction.

- Developing your own curriculum requires instructional design and course development skills. Some virtual leaders felt they needed product development and project management skills to successfully deliver high quality curriculum.

- Some courses can be particularly difficult to deliver in the online environment, i.e., art, music, or some special education services.

- We have to plan for attrition in a way that other schools do not, particularly for FTE. Sometimes, this means over-enrolling class sizes to be sure we end up where we need to be. 
Table 2 (continued)

P-SEL Standard Virtual Leadership Competencies

Community of Care and Support for Students

- Relationships must be developed virtually. A superintendent or principal cannot walk down the hall or visit the cafeteria to see students.

- All services and activities must be delivered virtually. (Clubs and activities must be offered online. If there is an in-person prom or graduation, this requires event planning and logistical skills as students may be coming in from all over the state.)

- Some schools hire and supervise regional event coordinators that can offer some local in-person activities or meetings.

- Some students find the virtual environment isolating and/or challenging. Many schools/ leaders have created new positions such as "academic success coordinators" or "instructional coaches" that support students with their academics.

- Some schools use online peer mentoring programs to assist in building community.

- Guidance and counseling services must be provided online and uphold strict confidentiality guidelines.

Professional Capacity of School Personnel

- Leaders are hiring for a different skill set.

- Teachers require extensive PD (technology, online pedagogy, online curriculum development, Competency-based learning, personalized learning, asynchronous instruction, flexibility, etc.).

- Teachers need to be flexible and willing to work with students working at different paces.

- In many cases, faculty meetings and PD must be done online.

- Maintaining a healthy work-life balance is different and can be difficult when working from home.

Professional Community for Teachers and Staff

- Leaders must build community virtually.

- Leaders must develop a sense of belonging virtually.

- Leaders must provide opportunities for interaction and collaboration virtually to promote mission.

- Communication must be very deliberate and clear.

- Communication must be frequent so people do not feel disconnected.

- Leaders need virtual sense of presence.

Meaningful Engagement of Families and Community • Families may be distributed over a large geographic area.

- Families must be engaged as partners, especially with the younger children as they serve as learning coaches.

- Families must receive training in the LMS or content delivery systems to support the younger children; they need training to help and monitor the older children.

- Families may need training and support to participate in communication, discussions, etc.

- Parental volunteer opportunities must be virtual.

- In some cases, the "community" consist of a very large geographical area or the whole state; this makes building community challenging for the virtual leader.

- Leaders often feel as though they have to prove themselves as some community members are skeptical of online learning.

Operations and Management

- Since they are typically schools of choice, leaders end up engaging in marketing or in hiring marketing and sales teams.

- Funding models can differ from typical district funding models. Some districts receive only partial FTE; some districts receive FTE only for students who successfully complete coursework. This requires different budgeting skills.

- Some leaders have to work with business partners, or Education Management Organizations (EMOs) and have to navigate these relationships. It is important to many to retain their own control and identities even if they have an EMO.

- Some schools partner with several brick-and-mortar schools in supporting traditional school attendance. Leaders need to build relationships with all of these schools. There are multiple superintendents or principals supporting the same students.

- Leaders have to have different technical apparatus to support students; LMS or CMS, provide computers or ensure students have computers, manage Internet access issues, need technology to promote communication and collaboration.

- Leaders have to be very cognizant of student privacy issues in the online environment as all data is online. Schools worry about data breaches and cyber ransom attacks. Many leaders have to hire cyber security professionals. 
Table 2 (continued)

\begin{tabular}{|c|c|}
\hline P-SEL Standard & Virtual Leadership Competencies \\
\hline School Improvement & $\begin{array}{l}\text { - Leaders have a lot of internal data points to examine. (Every click is captured online; } \\
\text { how long a student spent on each page, which pages they visited, which resources they } \\
\text { clicked into, all assessment data, etc.) } \\
\text { - Leaders have to worry about parent and student satisfaction in a way that other schools } \\
\text { do not since they are a choice. } \\
\text { - Sometimes student data is split across different schools and it can be difficult to develop } \\
\text { the whole picture on some students. } \\
\text { - Some schools do not receive student standardized testing data. } \\
\text { - State accountability and reporting rules may differ for charter or private schools. }\end{array}$ \\
\hline Other & $\begin{array}{l}\text { - Leaders reported having to frequently explain and defend online learning to others. } \\
\text { - Leaders felt as though some of their peer leaders in brick-and-mortar schools excluded } \\
\text { them either because they did not respect the work they do or because they were viewed } \\
\text { as competition for FTE. }\end{array}$ \\
\hline
\end{tabular}

partners because the children are too young to be at home alone and those that are still learning to read, need support with instructions. Ned reported, "I actually have to run professional development for parents because they have to know how to use the technology and support their kids."

Leaders also employed virtual clubs and activities as well as face to face events to promote a community of care and support for students as well as to meaningfully engage with families and communities. Several of the virtual schools served students from across the state. "One of the biggest challenges I have is that my community is spread across the entire state," Kelly stated. Chris reported that he has an Activities Director and 15 regional event coordinators to address this. Scott stated:

I never realized that I would be expected to be an event coordinator and handle all of the logistics associated with bringing in students and families from across the state. We bring them in for testing and we also do a face-to-face prom and graduation. I am renting facilities, managing travel and hotel arrangements...it was not what I expected.

Virtual leaders had to develop strategies to promote virtual connections and relationships as well as have the ability to leverage technology tools to do so. These connection and engagement challenges also required virtual leaders to take on new roles, adjust job descriptions, create new positions, and develop professional development related to the coaching of students and the engagement of their families.

Instructional support and supervision in virtual schools also require different skill sets. The reliance on a "home mentor," often a parent or guardian, is required in many of the virtual schools that serve younger children who are still developing the ability to read and comprehend information as well as to work independently. "We have specially designed trainings for parents and guardians so they know how to access and turn in assignments, monitor progress, and support students, without doing the work for them" Susan reported. Ned concurred stating, "We not only have to provide specialized training for instructors, but for parents, too." Several of the leaders reported that their teachers were surprised by how much more frequently they interacted with parents than in a traditional school. Jamie noted that at the high school level the teachers are speaking to every parent at least once a month.

Many of the virtual leaders reported that the initial training and professional development for online teachers must be different than for those teaching face-to-face. Almost all leaders reported that additional training is required for the technology systems that they use to support students such as a learning management systems (LMS) and other types of Web 2.0 communication tools. Diane noted that most teachers, "are not familiar with terms like synchronous and asynchronous instruction because they are only familiar with the face-face modality." Vicki noted, "We have to teach them about online pedagogy and aspects of instructional design." Many virtual leaders noted that they have to implement their teacher trainings online because of the regional diversity of their teaching staff.

Several of the virtual leaders expressed that teaching the technology components to new virtual teachers was the easiest part of their onboarding process. Many thought that helping teachers to see themselves as facilitators of instruction and to understand the flexibility required for online learning was much more difficult. Allison noted multiple conversations with teachers about students working at their own pace where teachers expressed frustration that "We're not preparing them for the real world." She explained that she has to coach them to think differently:

If you fail your driving test, you're not just done forever, you go back, you study some more, and you just take it again. The point is that you learn to drive. I mean people are late in paying their bills all of the 
time. There may be a late fee, but they still get to pay them. I also have to remind them that sometimes they are late in doing paperwork at school and we don't fire them. It's weird though because a lot of teachers think it is their job to be punitive and that this is in some way teaching kids a life lesson. I have to undo a lot of that thinking."

Several leaders expressed similar challenges since many of these schools have flexible pacing and mastery-based learning that requires flexibility on the part of the instructor. Additionally, some of the schools offer rolling enrollment, which means teachers have to be prepared to accept students year-round and there are no traditional marking periods or semesters.

Many virtual leaders viewed the teachers as facilitators of instruction and as instructional support interventionists. Jamie reported:

We have incredible fidelity and accountability with regard to standards alignment. In our case the curriculum is already developed with standards, content, and assessments. Then, we're teaching the teachers how to facilitate that content and guide students.

Holly relayed a similar experience:

Our curriculum is already developed so my teachers don't have to create lesson plans every day. However, they do have to understand curriculum, provide gap instruction, promote instructional intervention and monitor students to be sure that they are moving through the curriculum at an acceptable pace.

While many virtual schools do use pre-prepared course curriculum, others adapt pre-prepared curriculum, or develop their own online curriculum. Joseph noted:

We purchased a curriculum, but it can be customized so that teachers can make it stronger and make it their own. We collect feedback from students on every course to continue to improve them. We also use data to monitor student performance and if one lesson is taking everyone a particularly long time, we'll look at that.

For those schools that develop their own curriculum, leaders reported that academic integrity is a big area of concern for online schools. "The kids are right on the computer. They can Google anything, but that begs the question, then, if they can Google it, why are we asking them about it?" Lena questioned. A few of the other principals echoed similar concerns. Bobbie noted, "academic integrity used to be a much bigger issue but we have learned to create better assignments and assessments that are not easily copied or Googled and require more application of knowledge and skills." A few of the schools use oral assessments in addition to online assessments to ensure that the student is doing the work and understanding the concepts.

Observations can look very different in online schools. Gabe noted, "I can't just walk up and down the halls or do classroom walk-throughs exactly like I did in the traditional environment." Instead, virtual school leaders reported conducting data walk-throughs where they monitor teacher and student online activity. Some schools have systems that notify leaders if teachers have not recorded regular contact with students. Vicki reported, "I look for students who have not logged in or students that are not making sufficient progress in the data and then I connect with the teacher." Virtual observations can be synchronous or asynchronous depending on how the schools structure instruction. A few of the schools require some synchronous instruction and that teacher record all sessions with students so they are available for viewing by school leaders. Leaders reported looking for and assessing teacher online presence, rapport with students, student engagement and participation, the quality of questioning, and the accuracy of content in synchronous sessions. In asynchronous sessions, leaders reported looking for and assessing the turn-around time on assignments, feedback provided to students, motivational weekly updates, regular contact/communication, and instructional intervention.

Virtual leaders also reported being unprepared for some aspects of their work and indicated that they felt some business or non-profit leadership training would have helped them. The funding models for virtual schools differ greatly. Some are performance based, others earn only a portion of the state's FTE per student, some are FTE dependent but have high transient populations making budget predictions challenging. Others need to navigate partnerships with traditional districts or with education management organizations (EMO's). Joseph stated, "The biggest thing that I had to just basically learn on my own is the finance piece. I think I took one finance course, but as a charter school leader, in a lot of ways, you're the head of a nonprofit." John concurred, "Educational leadership programs for leaders of online schools, need to focus more on being a nonprofit leader than an education school leader. Of course, there is the academic piece, which is very important. But what you don't learn is finance, what you don't learn is marketing, what you don't learn are all the other things that go into running online school." Since virtual learning is a choice, several of the leaders mentioned the importance of having some background in sales and marketing. Additionally, several of the virtual schools develop their own online courses and felt that this required product development skills. "I've got project managers, instructional designers, content experts. It is a long and arduous process that is a lot more like developing a textbook for publication than a traditional district curriculum. I could have used some business skills." Scott stated. Leadership preparation 
programs need to strive for better alignment of coursework with the competencies required for virtual leadership.

\section{Discussion and Conclusions}

Virtual school leaders noted that the P-SEL standards categorically aligned with their work, but that there were very specific nuances that were unique to the online environment, such as communicating virtually with faculty, students, and parents, and delivering curriculum and instruction in the online environment. Further, all 23 of the school leaders who had participated in a traditional education leadership program for licensure communicated that these programs did not adequately prepare them for the work they do as virtual leaders. While little research has been done on the competencies required for effective virtual school leadership (McLeod \& Richardson, 2011; Richardson et al., 2015), it has become clear with the current pandemic that all school leaders need some competencies associated with virtual leadership as schools across the globe grappled with delivering content remotely.

The work of traditional school leaders changed considerably and possibly irreversibly during the pandemic (Francisco \& Nuqui, 2020; Harris \& Jones, 2020; Pollack, 2020. Leaders had to support teachers, students, and families to transition to remote learning, they needed to become experts in technology and online curriculum and instruction, they had to become chief communicators and policy interpreters as rules and regulations were being released without warning (Harris \& Jones, 2020; Pollack, 2020). They also had to manage the distance between school members working to engage students, motivate staff, communicate with families, and establish trust (Harris \& Jones; Pollack, 2020). These findings are consistent with the competencies virtual leaders identified as being important in their contexts.

Leadership continued to play an important role in student achievement during the pandemic. The biggest factor impacting teacher self-efficacy during the pandemic was effective school leadership (Kraft et al., 2020). Selfefficacy has been consistently recognized as an important attribute of effective teaching and has been positively correlated to teacher and student outcomes (TschannanMoran et al., 1998). Kraft et al. (2020) reported that teachers experienced challenges during the pandemic which included engaging students in the online remote environment and balancing professional and personal responsibilities working from home, resulting in on overall decline in teacher self-efficacy. Teachers in high-poverty and high minority schools perceived these challenges to be more severe (Kraft et al., 2020). Teachers who experienced strong school-based leadership that provided clear communication, meaningful collaboration, targeted training, fair expectations, and recognition of teacher effort, were least likely to experience declines in self-efficacy during the pandemic (Kraft et al., 2020).

Education leadership programs must be accountable for adequately preparing school leaders to effectively perform their responsibilities, especially those that serve our most vulnerable students. More attention must be paid to adequate school leader preparation with regard to virtual school leadership both for those who may lead virtual schools and those who may lead in brick-and-mortar schools but are running supplemental online programs or are implementing remote instruction because of an emergency. Francisco \& Nuqui (2020), Harris and Jones (2020), and Pollack (2020) found that school leadership preparation programs are out of alignment with the challenges leaders are facing today and that substantial revision is required to address the leadership skills relevant to the ongoing pandemic. Key competencies that need to be addressed were identified as knowledge of technology used for online learning, an understanding of online curriculum and pedagogy, the need to be able to operate and communicate in the online environment, crisis management, and an understanding of situational/contextual leadership Francisco \& Nuqui, 2020; Harris \& Jones, 2020; Pollack, 2020). It has also been recommended that leaders learn from one another's successes during the pandemic (Francisco \& Nuqui, 2020). Leaders were eager to learn from other leaders during the pandemic. Nine of the 28 school leaders who participated in this study were interviewed after March of 2020. During my interviews, 7 of the 9 virtual school leaders interviewed $(78 \%)$ indicated that they had been contacted by local brick and mortar school leaders requesting assistance with a variety of virtual leadership competencies.

While this study is not generalizable, it makes a valuable contribution to the scholarship to better understand the competencies required for virtual leadership. It is recommended that additional research be conducted to continue to examine the competencies required for virtual leadership, the competencies required for leading in blended school districts and the challenges faced by brick-and-mortar leaders during the pandemic.

Virtual school enrollment increased dramatically as a result of COVID-19 accounting for $40 \%$ of the decline in traditional schools and with most of this growth occurring in the elementary grades (Molnar et al., 2021). Even as the dangers of the COVID-19 pandemic diminish, Schwartz et al. (2020) reported that $20 \%$ of brick-and-mortar schools now plan to establish and expand online learning for the families who have enjoyed the flexibility provided by online learning. Every leader is now a virtual leader. Leadership preparations programs must effectually prepare all future leaders for the competencies required for virtual leadership. 


\section{Declarations}

Conflict of Interests/Competing Interests No funding was received to assist with the preparation of this manuscript.

\section{References}

Abrego, J., \& Pankake, A. (2010). PK-12 virtual schools: The challenges and roles of school leaders. Educational Considerations, $37(2), 7-13$

Adams, W. C. (2015). Conducting semi-structured interviews. In K. E. Newcomer, H. P. Hatry, \& J. C. Wholey (Eds.), Handbook of practical program evaluation (pp. 492-505). Jossey-Bass.

Andrews, R. L., \& Soder, R. (1987). Principal leadership and student achievement. Education Leader, 44(2), 9-11.

Barbour, M. K., LaBonte, R., Kelly, K., Hodges, C., Moore, S., Lockee, B., Trust, T., Bond, A., \& Hill, P. (2020). Understanding pandemic pedagogy: Differences between emergency remote, remote, and online teaching. Canadian eLearning Network. https://k12sotn.ca/wp-content/uploads/2020/12/under standing-pandemic-pedagogy.pdf

Baumbusch, J. (2010). Semi-structured interviewing in practice Close research. Journal for Specialists in Pediatric Medicine, 15(3), 255-258.

Beauchamp, G., Hulme, M., Clarke, L., Hamilton, L., \& Harvey, J. A. (2021). 'People miss people:' A study of school leadership and management in the four nations of the United Kingdom in the early stage of the pandemic. Educational Management Administration and Leadership, 49(3), 375-392.

Bernard, R. H. (2012). Social research methods: Qualitative and quantitative approaches (2nd ed.). Sage.

Bossert, S.T., Dwyer, D.C., Rowan, B., \& Lee, G.V. (1982). The instructional management role of the principal. Education Administration Quarterly, 18(3), 34-64.

Crabtree, B. F., \& Miller, W. L. (1999). Clinical research: A multimethod typology. In B. F. Crabtree \& W. C. Miller (Eds.), Doing qualitative research (2nd ed., pp. 3-32). Sage Publications, Inc.

Creswell, J. (2003). Research design: Qualitative, quantitative, and mixed methods approaches. Sage.

Day, C., \& Gurr, D. (Eds) (2014). Leading schools successfully: Stories from the field.Routledge.

Day, C., \& Leithwood, K. (2007). Successful principal leadership in times of change. Springer.

DiCicco-Bloom, B., \& Crabtree, B. F. (2006). The qualitative research interview. Medical Education, 40, 314-321.

Francisco, C.D.C., Nuqui, A.V. (2020) Emergence of a situational leadership during COVID-19 pandemic called new normal leadership. International Journal of Interdisciplinary Research, 4(10), 15-19.

Fereday, J., \& Muir-Cochrane. (2006). Demonstrating rigor using thematic analysis: A hybrid approach of inductive and deductive coding and theme development. International Journal of Qualitative Methods, 5(1), 80-92.

Galleta, A. M. (2013). Mastering the semi-structured interview and beyond. NYU Press.

Gemin, B., Pape L., Vashaw, L., \& Watson, J. (2015). Keeping pace with K-12 digital learning: An annual review of policy and practice. Evergreen Education Group. https://static1.squar espace.com/static/59381b9a17bffc68bf625df4/t/5949b64bb1 1 be 1 ad7855fb51/1498003034517/KeepingPace+2015.pdf
Guest, G., Bunce, A., \& Johnson, L. (2006). How many interviews are enough? An experiment with data saturation and variability. Field Methods, 18(1), 59-82. https://doi.org/10.1177/15258 22X05279903

Gurr, D. \& Day, C. (2014). Thinking about leading schools. In C. Day \& D. Gurr (Eds.), Leading schools successfully: Stories from the field. (pp. 194-208). Routledge.

Hallinger, P. (2018). Bringing context out of the shadows of leadership. EducationalManagement, Administration and Leadership. $46(1), 5-24$

Harris, A., \& Jones, M. (2020). COVID-19-school leadership in disruptive times. School Leadership and Management, 40(4), 243-247.

Hobbs, T.D., \& Hawkins, L. (2020). The results are in for remote learning: It didn't work. The Wall Street Journal. https://www. wsj.com/articles/schools-coronavirus-remote-learning-lockd own-tech-11591375078.

Hodges, C., Moore, S., Locke, B., Trust, T. \& Bonda, A. (2020). The difference between emergency remote teaching and online learning. Educause Review. https://er.educause.edu/articles/ 2020/3/the-difference-between-emergency-remote-teachingand-online-learning

Jacobson S., Day C., \& Leithwood K. (Eds.). (2005). The international successful schoolprincipalship project. Journal of Educational Administration, 43, 532-629.

Johnson, G. \& Dempster, N. (2016) Leadership in diverse learning contexts. Springer.

Kraft, M.A., Simon, N.S., \& Lyon, M. A. (2020). Sustaining a sense of success: The importance of teacher working conditions during the COVID-19 pandemic. (EdWorkingPaper: 20-279). Annenberg Institute at Brown University. https://doi.org/10. 26300/35nj-v890

La France, J. A., \& Beck, D. (2014). Mapping the terrain: Education leadership field experiences in K-12 virtual schools. Educational Administration Quarterly, 50(11), 160-189.

Leithwood, K. A., \& Jantzi, D. (2008). Linking leadership to student learning: The contributions of leader efficacy. Educational Administration Quarterly, 44(4), 496-528.

Lord, R.G., Brown, D.J., Harvey, J.L., \& Hall, R.J. ( 2001). Contextual constraints onprototype generation and their multilevel consequences for leadership perceptions.Leadership Quarterly, $12,311-338$.

Mason, M. (2010). Sample size and saturation in PhD studies using qualitative interviews. Forum: Qualitative Social Research, 11(3). https://doi.org/10.17169/fqs-11.3.1428

McLeod, S., \& Richardson, J. W. (2011). The dearth of technology coverage. Journal of School Leadership, 21(2), 216-240.

Mertler, C. (2014). Action research: Improving schools and empowering educators. SAGE Publishers, Inc.

Molnar, A. (Ed.) (Ed.), Rice, J. K., Huerta, L., Shafer, S. R., Barbour, M. K., Miron, G., Gulosino, C, Horvitz, B. (2014). Virtual schools in the U.S. 2014: Politics, performance, policy, and research evidence. National Education Policy Center. https:// nepc.colorado.edu/publication/virtual-schools-annual-2014

Molnar, A., Miron, G., Elgeberi, N., Barbour, M. K., Huerta, L., Shafer, S. R., \& Rice, J. K. (2019). Virtual schools in the U.S. 2019. National Education Policy Center. http://nepc.colorado. edu/publication/virtual-schools-annual-2019.

Molnar, A. (Ed.) (Ed.), Miron, G., Barbour, M.K., Huerta, L., Shafer, S.R., Rice, J.K., Glover, A., Browning, N., Hagle, S., \& Boninger, F. (2021). Virtual schools in the U.S. 2021. National Education Policy Center. http://nepc.colorado.edu/publication/virtu al-schools-annual-2021 
Moos, L., Johansson, O., \& Day, C. (Eds.). (2011). How school principals. sustain successover time: International perspectives. Springer.

National Association of Elementary School Principals. (2020). NAESP releases results of National Survey of principals regarding COVID-19, march 31. https://www.naesp.org/content/naespreleases-results-national-survey-principals-regarding-covid-19

Noman, M. \& Gurr, D. (2020) Contextual leadership and culture in education, In G.W. Nobit (Ed.), Oxford Research Encyclopedia of Education ( pp. 20). Oxford University Press. https://doi.org/ 10.1093/acrefore/9780190264093.013.595

Patton, M. Q. (1990). Qualitative evaluation and research methods. Sage.

Pokhrel, S., \& Chhetri, R. (2021). A literature review on impact of COVID-19 pandemic on teaching and learning. Higher Education for the Future, 8(1), 133-141.

Pollack, K. (2020). School leaders' work during the COVID-19 pandemic: A two-pronged approach. International Studies in Education, 48(3), 38-44.

Professional Standards for Educational Leaders. (2015). National policy board for educational administration. https://www.npbea. org/psel/

Quillici, S.B., \& Joki, R. (2011-2012). Investigating roles of online school principals. Journal of Research on Technology in Education, 44(2), 141-160.

Richardson, J. W., LaFrance, J., \& Beck, D. (2015). Challenges of virtual school leadership. American Journal of Distance Education, 29(1), 18-29. https://doi.org/10.1080/08923647.2015.992647
Ryan, F., Coughlan, M., \& Cronin, P. (2009). Interviewing in qualitative research: The one-to-one interview. International Journal of Therapy and Rehabilitation, 16(6), 309-314.

Schwartz, H. L., Grant, D., Diliberti, M., Hunter, G. P., \& Setodji, C. M. (2020). Remote learning is here to stay: Results from the first American school district panel survey. Rand Corporation. https:// doi.org/10.7249/RRA956-1

Tschannan-Moran, M., Hoy, A. W., \& Hoy, W. K. (1998). Teacher efficacy: Its meaning and measure. Review of Educational Research, 68(2), 202-248.

Varela, D. G., \& Fedynich, L. (2020). Leading schools from a social distance: Surveying South Texas school district leadership during the COVID-19 pandemic. National Forum of Educational Administration and Supervision Journal, 38(4), 1-10.

Waters, T. J., \& Marzano, R. J. (2007). School leadership that works: The effect of superintendent leadership on student achievement. ERS Spectrum, 25(2), 1-12.

Publisher's Note Springer Nature remains neutral with regard to jurisdictional claims in published maps and institutional affiliations. 